\title{
Los puentes entre Manuel Vázquez Montalbán y el EZLN: cronología e intercambio textuales (I) ${ }^{1}$
}

\author{
SERGio García García \\ Instituto de Investigaciones Filológicas \\ (Universidad Nacional Autónoma de México)
}

Resumen: Este estudio, dividido en dos partes, tiene como propósito principal la realización y el análisis del corpus de los textos periodísticos, ensayísticos y de ficción que Manuel Vázquez Montalbán dedicó a la causa del EZLN entre 1994 y 2003; asimismo, presta atención a la relación de este autor con el subcomandante Marcos, con el fin de determinar un imaginario global montalbaniano en torno al neozapatismo. Además, la relación del escritor con Chiapas se complementa con el estudio de varias obras de Marcos donde Vázquez Montalbán aparece como referente intelectual y como materia literaria, entre las que destaca la novela Muertos incómodos (falta lo que falta), escrita junto con Paco Ignacio Taibo II.

Palabras clave: Manuel Vázquez Montalbán; neozapatismo; periodismo; Marcos: El señor de los espejos; Subcomandante Marcos; Muertos incómodos.

\section{The bridges between Manuel Vázquez Montalbán and EZLN: chronology and textual exchange}

Abstract: The main purpose of this study, divided in two parts, is to carry out and analyze the corpus of journalistic, essay and fiction texts that Manuel Vázquez Montalbán dedicated to the EZLN cause between 1994 and 2003, also paying attention to his relationship with Subcomandante Marcos, in order to determine a global Montalbanian imaginary around neozapatism. In addition, the writer's relationship with Chiapas is complemented by the study of several works by Marcos where Vázquez Montalbán appears as an intellectual reference and as a literary object, among which the novel The uncomfortable dead (what's missing is missing), written together with Paco Ignacio Taibo II.

Key Words: Manuel Vázquez Montalbán; Neozapatism; Journalism; Marcos: El señor de los espejos; Subcomandante Marcos; The Uncomfortable Dead.

1 Este estudio se inscribe dentro del proyecto de investigación posdoctoral titulado «Noticia de Manuel Vázquez Montalbán en México: testimonio, publicaciones y recepción», auspiciado por el Programa de Becas Posdoctorales de la UNAM (periodo 2020-I) y asesorado por la Dra. Tatiana Aguilar-Álvarez Bay del Instituto de Investigaciones Filológicas. 


\section{Introducción}

\section{omo fruto de uno de sus primeros viajes a México, en los que re- corrió Baja California Sur y Ciudad de México, el escritor barcelo- nés Manuel Vázquez Montalbán (1939-2003) publicó en el diario El País el 27 de marzo de 1984 un texto titulado «Las señoritas del abanico», en el que se puede leer lo siguiente:}

Mientras tanto, millones y millones de herederos directos y puros de aquellos habitantes precolombinos, pasados por la piedra y por la España de la conquista, arrastran una difícil supervivencia, sometidos ahora ya no al poder imperial de los reyes de España, sino al poder económico, político y social de un bloque hegemónico que amalgama a herederos del criollismo, inmigrantes aposentados y managers de compañías multinacionales apátridas, como el dinero mismo. [...] Los indígenas de a pie, los peatones del indigenismo, se han quedado a solas con una geografía inmediata, en la que el bien y el mal cósmico no es histórico, en el mejor de los casos es un bien o un mal que recibe de la naturaleza, y en el peor, que le impone un neocolonizador hecho a imagen y semejanza de los colonizadores de siempre, si a este indígena auténticamente precolombino no le quitan la geografía, no le destruyen para meter las autopistas en las selvas y el capitalismo agrario en los campos roturados, algún día exigirá un protagonismo histórico, hasta ahora negado, y exhibirá un memorial de agravios en el que no se salva ni Dios. Es un decir (Vázquez Montalbán, 1984).

Al margen del posible carácter profético de sus palabras, cabe señalar cómo ya a mediados de los años ochenta Vázquez Montalbán poseía un cierto interés y una cierta sensibilidad hacia la realidad político-social mexicana. A partir de los noventa, su obra se vio marcada por «un cambio de actitud ante la historia y el presente, que determina un cambio de rumbo de las estrategias textuales e intelectuales del autor» (Balibrea Enríquez, 2002: 207-208): «la constatación de los efectos devastadores de la globalización y la búsqueda de posibles vías de resistencia» (Colmeiro, 2013: 43), cuyas principales reflexiones sobre esta cuestión se condensan en su ensayo Panfleto desde el planeta de los simios (1995). Aunque ya a finales de 1973 apareciera por primera vez la realidad latinoamericana en la obra montalbanina con el libro $L a$ vía chilena al golpe de estado, desde la caída del muro de Berlín, Latinoamérica como tema adquirió una notable presencia dentro de su producción narra- 
tiva y ensayística, no solo porque con su mirada hacia el continente el escritor trate «de hallar una esperanza de futuro a los retos de la globalización» (Colmeiro, 2014: 294), sino porque también, en palabras de Francesc Salgado,

Latinoamérica se convierte, y no solo por el tránsito de la actualidad, en un centro de interés para Vázquez Montalbán porque expresa la tensión producida por la irrupción de los incipientes principios del neoliberalismo con una situación de pobreza estructural que, si bien una economía socializada y de interés público podría revertir, corría el peligro de ser sometida a los principios económicos neoliberales más agudos, una especie de laboratorio del futuro (2020: 14).

Todo ello justifica la implicación de Vázquez Montalbán en el alzamiento del Ejército Zapatista de Liberación Nacional (EZLN) el 1 de enero de 1994 en el estado mexicano de Chiapas y en todo lo acaecido posteriormente; como asegura Salgado, «nunca se implicó tanto en una revolución como en la zapatista» (2020: 23).

Vázquez Montalbán fue uno de los muchos escritores extranjeros que se solidarizaron con el movimiento neozapatista (Lario Bastida, 2019) y posiblemente, dentro del panorama español, el que tuvo una mayor involucración y visibilidad. Su imaginario ideológico en torno al EZLN debe determinarse a partir de los numerosos textos que dedicó a esta cuestión. No solo debe tenerse en cuenta su libro Marcos: El señor de los espejos, publicado en septiembre de 1999 por Aguilar, cuyo eje central es el viaje que realizó a la Selva Lacandona en 1999 para entrevistar al Subcomandante Insurgente Marcos, y que sin duda se ha convertido en una de las principales referencias de la bibliografía dedicada al neozapatismo, sino también las columnas de opinión y reportajes que publicó en la prensa española entre 1994 y $2002^{2}$, así como las breves alusiones al movimiento recogidas en sus ensayos y obras de ficción. Asimismo, para que esta relación entre el barcelonés y el EzLN sea completa, es preciso localizar y analizar todas las referencias al propio Vázquez Montalbán incluidas en las cartas, los comunicados y las obras literarias de Marcos, además del papel capital que desempeña su figura en la novela Muertos incómodos (falta lo que falta) (2005), escrita junto con Paco Ignacio Taibo II.

2 No se han incluido en este estudio los posibles textos que Vázquez Montalbán publicara en la prensa mexicana, debido a que su búsqueda y análisis se corresponde con el segundo periodo del proyecto de investigación posdoctoral en el que se enmarca este estudio. 
La mejor manera de definir el vínculo ideológico entre Vázquez Montalbán y el EZLN - representado sobremanera en la figura de Marcos - , y de base sobre todo textual, podría ser a partir de la metáfora del puente, utilizando las palabras que el subcomandante dedicó al barcelonés en el homenaje que se le rindió en la Feria Internacional del Libro de Guadalajara el 28 de noviembre de 2004, en la edición dedicada a Cataluña:

Al hablar de él trato, de no traerlo con nosotros o a favor nuestro, sino de volver a tenderlo como lo que fue: un puente. Y, a lo mejor, aún sin estar, Don Vázquez Montalbán vuelve a ser un puente para que nuestra palabra, la de los zapatistas hoy no tan de moda, tenga un lugar entre tantos genios de la palabra como ahora se encuentran en tierras mexicanas. [...] $\mathrm{Si}$ alguien me pidiera un ejemplo que sintetizara la resistencia de la humanidad frente a la guerra neoliberal, diría que la palabra. Y agregaría que una de sus trincheras más empecinada, y afortunadas, es el libro. Aunque, claro, es una trinchera muy otra porque se parece extraordinariamente a un puente. Porque quien escribe un libro y quien lo lee no hacen sino cruzar un puente. Y el cruzar puentes, viene en cualquier manual de antropología que se respete, es una de las características de ser humano. [...] Si alguien me pidiera una definición de Don Manuel Vázquez Montalbán diría que fue, y es, un puente (Marcos, 2004).

\section{Primeros acercamientos al EZLN (1994-1997)}

El 9 de enero de 1994 Vázquez Montalbán decidió dedicar su columna de opinión en la última página del diario El País, que estuvo escribiendo desde enero de 1984 hasta su muerte, en octubre de 2003 (Geli y Mauri, 2008: 357), y cuyos textos se caracterizan por un registro que supone una mezcla de «ironía, brillantez y creatividad» (Salgado 2012: 18), al alzamiento del EZLN acaecido algunos días antes. Con este primer texto dedicado al neozapatismo, de título «Chiapas», el escritor «prepara el camino que lo convertirá en

\footnotetext{
3 En el acto de homenaje participaron Pascual Maragall, José Saramago, Rosa Regàs, Jordi Puntí, Carlos Monsiváis, la viuda del escritor Anna Sallés y Sealtiel Alatriste, quien editó en México Marcos. El texto del subcomadante fue enviado personalmente a Sallés y a Daniel Vázquez Sallés, hijo de Vázquez Montalbán, para que se leyera en el homenaje. El acto, aun así, no estuvo exento de polémica, ya que la prensa acusó erróneamente a Alatriste, el coordinador, de censurar la carta de Marcos, que no se leyó completa realmente por falta de tiempo. Alatriste explicó los hechos en su texto "Sin censura. Sobre información y mala leche", publicado en La Jornada (01/12/2004).
} 
uno de los hagiógrafos oficiales del subcomandante Marcos» (Volpi, 2018: 269). «Chiapas» fue una respuesta al texto «El nudo de Chiapas», que Octavio Paz publicó en La Jornada el 5 de enero - fue reproducido a su vez en El País dos días después -, en el cual aseguraba que «la revuelta de Chiapas es un fenómeno que corresponde a las condiciones peculiares de esa región», palabras que reprodujo el barcelonés en su columna para afirmar después que "Chiapas no es tan peculiar» y que «el inmenso Chiapas de la aldea global no tiene quien le escriba ni quien le permita ratificar su identidad, y cuando ejerce el lenguaje de la revuelta se atribuye a la inspiración de revolucionarios urbanos, señoritos del marxismo residual o de la teología de la liberación que hinchan la cabeza a los condenados de la tierra para impedirles ver las ventajas del GATT, del TLC o del TAV» (Vázquez Montalbán, 1994a). Con «Chiapas» Vázquez Montalbán comenzó a asentar las bases de un discurso condenatorio hacia la globalización y hacia esa teología neoliberal que dará pie al mismo tiempo a otro discurso de reivindicación constante del neozapatismo. En su segundo texto dedicado a los sucesos de Chiapas, «La teología neoliberal» (El País, 05/04/1994), atacó a esta nueva teología y a sus miembros, pertenecientes a la derecha ultraliberal, «supervivientes a la muerte de los profetas, avalados por un respaldo de medios de comunicación a veces sonrojante» y que establecieron que el asesinato de Luis Donaldo Colosio el 23 de marzo de ese mismo año en Tijuana «es consecuencia de la mitificación de la violencia justiciera experimentada con la revuelta de Chiapas. [...] Como si la cultura de la violencia presente en la vida política y social mexicana hubiera necesitado de la revuelta zapatista para salir de la nada o del limbo» (Vázquez Montalbán ,1994b). Este texto lo incluyó al año siguiente en Panfleto desde el planeta de los simios (1995: 72-76), la obra montalbaniana más citada por Marcos; es más, este comenzó su conversación con el escritor en la Selva Lacandona aludiendo a dicho libro: «A ver si te sale como Panfleto desde el planeta de los simios. Prácticamente se adelantó a muchos de nuestros planteamientos» (en Vázquez Montalbán, 2001a: 141) .

\footnotetext{
4 Para Balibrea la influencia de este libro en la monografía montalbaniana dedicada a Marcos es clara, incluso presenta a la segunda como heredera ideológica de la primera: «Que Marcos, el señor de los espejos es una respuesta a los llamados y propuestas especulativas que han caracterizado la obra de Manuel Vázquez Montalbán en los noventa, se hace ya patente en el subtítulo que se le da de Viaje desde el planeta de los simios a la selva Lacandona, que invoca el título del ensayo del autor de 1995, y el género mismo de aquél, pues también el Marcos es catalogado de panfleto» (2002: 217).
} 
Vázquez Montalbán no volvió a abordar el tema neozapatista hasta tres años después, con una columna de nuevo publicada en El País (03/02/1997) y titulada «Zapatismo». Cabe otorgar a este texto una relevancia especial de la cronología del escritor con el EZLN, ya que con él se inicia su relación directa con el subcomandante. Lo interesante de «Zapatismo» es que abre una línea en el discurso montalbaniano en la que la lucha del EzLN se reduce directamente a la figura de Marcos: afirmaciones como «el subcomandante Marcos trató de hacer una revolución después de la revolución» (Vázquez Montalbán, 2001b: 225), recogida en su ensayo La literatura en la construcción de la ciudad democrática (1998), o la recurrente identificación de Marcos con el Che Guevara ${ }^{5}$, lo elevan a una condición de líder indiscutible del EZLN, además de ser su voz y su cabeza visible ${ }^{6}$. Regresando a «Zapatismo», al final del texto Vázquez Montalbán alude a lo que debería considerarse como la génesis de la relación entre ambos y de su futuro viaje a Chiapas: en una entrevista para Televisión Española había escuchado que el subcomandante «había dejado de leer las novelas de Carvalho porque no podía resistir las recetas» - es de sobra conocido el carácter gourmet del principal personaje del barcelonés, el detective Pepe Carvalho, así como de su autor - , por lo que se proponía «instar a Carvalho a adecuar sus menús a la intendencia zapatista, según las claves de la cocina precolombina» (Vázquez Montalbán, 2012b: 278) y más acorde con las posibilidades alimenticias lacandonas, partiendo asimismo, en palabras de Colmeiro, «del deber ético de no contribuir al desánimo de los indígenas luchadores contra la globalización» (2010: 487). La historia

\footnotetext{
5 «Interesante la oposición del imaginario del guerrillero incomunicado, Guevara, y del guerrillero mediático, el subcomandante Marcos, tal vez Guevara el último representante de la dramaturgia de la revolución armada y Marcos el primero de la revolución televisada. En cualquier caso los dos son hijos de aquel encuentro mágico entre Marx y Rimbaud soñado en todos los mayos de los años sesenta: cambiar la vida, cambiar la Historia» (Vázquez Montalbán, 1997a: 14). Estas palabras parten del prólogo que escribió Vázquez Montalbán para la traducción española del libro Che. Ernesto Guevara, una leyenda de nuestro tiempo, de Pierre Kalfon. La comparación entre ambos guerrilleros que realiza Kalfon la asumió el barcelonés como uno de sus leitmotive sobre el neozapatismo, de ahí que lo anteriormente citado se pueda encontrar también en su artículo «El Che en el supermercado de la transgresión», publicado originalmente en francés en Le Monde (09/10/1997) (2012a: 302); en su libro Y Dios entró en La Habana (1998: 687-688); en su prólogo a la obra colectiva Geopolítica del caos. Le Monde diplomatique, edición española (1999a: 15), y, por supuesto, en Marcos (2001a: 23).

6 La focalización, en numerosas ocasiones, de todo el movimiento neozapatista en el propio Marcos por parte de Vázquez Montalbán, lo cual denota también una gran admiración hacia él, puede responder perfectamente a lo planteado por Jorge Volpi: «Si Marcos recibió el apoyo de tantos intelectuales en tantas partes del mundo, se debió a que ellos veían en él a otro intelectual» y «Visto en retrospectiva, el subcomandante encarna el ideal de muchos de sus corresponsales: un hombre de ideas que, impulsado por su deseo de transformar el mundo, decidió convertirse en un hombre de acción» $(2018: 132,394)$.
} 
que sigue a continuación, posiblemente debido a su carácter anecdótico y al intercambio de textos entre ambos, es de sobra conocida y ha sido relatada tanto por varios críticos como por el propio Vázquez Montalbán en varias ocasiones $^{7}$; no obstante, conviene dedicarle algunas páginas.

\section{El contacto con el subcomandante Marcos (1997-1999)}

Tiempo después de la publicación de «Zapatismo» en El País, a Vázquez Montalbán le hicieron llegar dos cartas a Barcelona de Marcos dirigidas a él y a Pepe Carvalho, y fechadas en diciembre de 1997. La primera de ellas, que el escritor recogió de manera íntegra en Y Dios entró en La Habana (1998a: 705-709) - un extenso ensayo dedicado al castrismo y a la visita que hizo Juan Pablo II a Cuba en enero de 1998 - y en Marcos (2001a: 26-32), va dirigida a «Manuel Vázquez Montalbán y/o Pepe Carvalho». A pesar de esta ambigüedad identitaria inicial, en la que se confunde al creador con la creación, y de que a lo largo de toda la misiva se dirija solamente al escritor barcelonés, Marcos trata a Carvalho como si fuera un personaje real - «quisiera pedirle que salude de mi parte a don Pepe Carvalho» (en Vázquez Montalbán, 2001a: 27) - y, en momentos puntuales, se refiere a los dos juntos, representando a cada uno como una realidad diferente, pero como si fueran una suerte de pareja inseparable: «Así que los vemos a ambos (usted y don Pepe) tratando de resolver los enigmas que los dos mundos les y nos plantean, $\mathrm{y}$, a nuestro modo y desde acá, los acompañamos» (en 2001a: 29-30). Es preciso resaltar esta actitud del subcomandante, ya que no solo está presagiando con ella el futuro papel de Vázquez Montalbán en la novela Muertos incómodos, sino que da cuenta de que le está escribiendo al autor de novelas policiacas ante todo, relegando a breves alusiones al intelectual español de izquierdas que ya venía denunciando desde hace años los principales problemas que propiciaron la aparición del EZLN. En su carta, Marcos dedica largos párrafos a demostrar su conocimiento de la producción negrocriminal de Vázquez Montalbán8: rememora el hábito de quemar libros de Carvalho, aplaudido en la Selva Lacandona; la

\footnotetext{
7 Véase, por ejemplo, Martí-Olivella (2007: 239-240) y Colmeiro (2010: 487-488), así como las obras montalbanianas Y Dios entró en La Habana (Vázquez Montalbán, 1998a: 704-712) y Marcos (2001a: 23-40, 63-77).

8 Y así se lo comenta a Vázquez Montalbán en su encuentro en la Selva Lacandona: el EzLN «es un ejército con una vida cultural muy intensa. De hecho a ti te leímos en la montaña, no en una librería, ni en un café, ni en una conferencia. Sino aquí en la selva, a través de Carvalho» (en Vázquez Montalbán, 2001a: 235).
} 
afición del detective por la buena cocina, lo cual hace que este texto sirva como respuesta a la columna «Zapatismo» - «Dígale usted [a Carvalho] que no le guardo rencor por la tortura que significó para mí, en aquellos primeros años de montaña (1984-1990), la lectura de sus aventuras gastronómicas, policíacas y amorosas» (en 2001a: 27) - , y recuerda cómo entre las pertenencias de uno de sus compañeros caído el 1 de enero encontraron un ejemplar de la novela carvalhiana Asesinato en el Comité Central (1981). En este punto, Marcos vuelve a presentarse como un gran lector de Vázquez Montalbán cuando advierte que Carmela, uno de los personajes principales de esta novela, reaparece en otra obra de la serie de Carvalho, El premio (1996), «pero ahora ella está en un comité de solidaridad con Chiapas - escribe el subcomandante- ${ }^{9}$. Así que las montañas del sureste mexicano y don Pepe se vuelven a encontrar 13 años después...» (en Vázquez Montalbán 2001a: 29). Aun así, el subcomandante ya había mostrado su gusto por las novelas de Vázquez Montalbán a través de uno de sus personajes literarios, don Durito de la Lacandona, dentro del libro homónimo que protagoniza el escarabajo, publicado en 1999: en uno de los comunicados que lo conforman, fechados entre 1995 y 1996, el narrador escribe que don Durito, un apasionado del género negrocriminal (Vanden Berghe, 2009: 255), «continúa leyendo una novela policiaca que le mandó, para que le dé su opinión, Manuel Vázquez Montalbán» (Marcos, 1999: 110) ${ }^{10}$.

De la segunda carta enviada por el subcomandante solo se tiene noticia gracias a los comentarios que de ella realiza el propio Vázquez Montalbán: «La otra carta fijaba posibilidades de encuentro, cómo, cuándo, y la ironía de si podría llevarle unos chorizos. ¿Por qué gustarán tanto los chorizos en el Trópico?» (2001a: 32). La respuesta montalbaniana a la propuesta del sub-

9 Que Marcos se considere un ávido lector de las obras de Vázquez Montalbán lo confirma que la alusión al apoyo de Carmela a la causa neozapatista, y que realiza su hijo en El premio, es bastante breve y algo velada, como se puede apreciar a continuación:

«- ¿Su madre todavía es comunista? - Ella dice que no, pero sigue a Anguita como si fuera Michael Jackson y Anguita tiene algo de Jackson, es un rojeras blanqueado o un blanco enrojecido. Mi madre está apuntada a todas las sociedades secretas del rojerío: SOS Racismo, Derechos Humanos, Fuera las manos de Chiapas...» (Vázquez Montalbán 1996: 77).

10 El escritor barcelonés es consciente de ello, como le asegura al subcomandante en Marcos: «Durito [...] me parece el más consistente [de tus personajes], y no es porque lea mis obras, según cuentas en un relato, sino porque es el que te permite decir más cosas y con mayor libertad» (Vázquez Montalbán, 2001a: 216). Incluso en una de sus columnas de El País, «Tam tam» (30/08/1999), dedicada a una manifestación producida en la Plaza de Cataluña de Barcelona en apoyo al EzLN, Vázquez Montalbán incluyó brevemente a Durito como personaje: «¿Qué es el zapatismo?, preguntaban, y el filósofo escarabajo Durito, enviado del subcomandante Marcos, contestaba: “Un síntoma de que el milenio trae una tensión dialéctica del carajo: globalizados contra globalizadores"» (1999c). 
Los puentes entre Manuel Vázquez Montalbán y el Ezln: cronología e intercambio...

comandante fue también epistolar, y estuvo acompañada por varios libros, entre ellos Panfleto desde el planeta de los simios; dicha carta se puede encontrar de manera íntegra - en Marcos solo se recoge un fragmento - en el epílogo de Y Dios entró en La Habana ${ }^{11}$, donde Vázquez Montalbán recogió el primer testimonio de su intercambio epistolar con el subcomandante y dejó clara su intención de mantener un encuentro con él en un futuro. En su respuesta desde Barcelona se hace patente su notable admiración hacia la causa neozapatista, basándose en lo que supuso en aquellos años la aparición del EZLN:

Lamento las hambres reales o imaginarias que le ha causado Carvalho y veo difícil superar con chorizos los obstáculos que nos separan [...]. Ustedes han construido un referente ético inatacable, de ahí su peligrosidad en un mercado político cultural tan devaluado éticamente. También representa lo nuevo después de la ruina de lo inevitable, del final infeliz de la dialéctica de los bloques que hay llevado a la globalización de la doble verdad, la doble moral, el doble lenguaje, la doble contabilidad. Había que retomar el discurso emancipatorio desde las realidades que lo hacen necesario, desde el inventario de necesidades colectivas reales creadas por la desigualdad y la injusticia. [...] Ustedes son un ruido en el canal de comunicación del pensamiento único. ¡Y vaya ruido! (Vázquez Montalbán, 1998a: 709-710)².

$\mathrm{Al}$ poco de que las dos cartas procedentes de Chiapas llegaran a Barcelona, se produjo la masacre de Acteal el 22 de diciembre de 1997. Vázquez Montalbán siguió la matanza gracias al testimonio de amigos suyos, como Teresa Nuibó, y de Daniel Vázquez Sallés, su hijo, que estuvo grabando en

11 Vázquez Montalbán presentó este libro en Ciudad de México en 1999 tras su estancia en San Cristóbal de las Casas: «Hay que volver a México D. F., presentar Y Dios entró en La Habana ante unos periodistas sorprendidos de que haya pasado primero secretamente por Chiapas y que dedique a esta primera presentación de mi libro apenas unas horas. La rueda de prensa que me organiza Laura Lara en representación de Santillana, da pie a preguntas concretas sobre un posible encuentro con Marcos y a respuestas ambiguas» (2001a: 326). Se conoce otra presentación del libro en Ciudad de México: fue el 27 de abril de ese mismo año en la Casa de la Cultura Jesús Reyes Heroles, en Coyoacán, junto con Adolfo Sánchez Vázquez y Paco Ignacio Taibo II, según la crónica que Mónica Mateos escribió para La Jornada y en la que también se descubre el vaticinio del futuro discurso prozapatista del barcelonés (Mateos, 1999). Asimismo, en el epílogo de Y Dios entró en La Habana Vázquez Montalbán da a entender que, en palabras de Albrecht Buschmann, «la respuesta a la cuestión sobre el futuro de la revolución no tiene tanto que ver con Cuba, como sugiere el título y esa continua preocupación por la isla, sino con México, en la Selva Lacandona» (2020: 52).

12 Al final de su carta, Vázquez Montalbán hace un guiño a las despedidas que incluye Marcos en todos sus textos - «Desde las montañas del Sureste Mexicano» -: «Desde una acomodada montaña que vigila Barcelona" » (Vázquez Montalbán, 1998a: 711), con la que alude a su domicilio en el barrio de Vallvidrera, donde también reside el detective Carvalho, situado en la sierra de Collserola, al noroeste de la ciudad. 
Chiapas los hechos posteriores. Además, en cuatro de sus columnas de $E l$ País que fueron apareciendo a lo largo de los meses siguientes denunció los sucesos de $\mathrm{Acteal}^{13}$, poniendo especial énfasis en los intentos del gobierno del Partido Revolucionario Institucional (PRI) por crear una versión diferente de la naturaleza y atribución de la matanza, como escribió en la primera de sus columnas dedicadas a esta cuestión: «Los desesperados intentos del PRI para disfrazar la última matanza de Chiapas como un pleito entre indígenas pretendían desacreditar a la revolución zapatista y justificar cualquier intervención militar futura para restablecer el orden. [...] Los caciques locales están exasperados por la estabilización del Frente Zapatista y sus posibilidades como movimiento político generador» (Vázquez Montalbán, 1997b). En resumidas cuentas, y como explicó en Y Dios entró en La Habana, «la matanza de Acteal inició el acoso de los zapatistas en cuatro frentes: el del PRI, el del Ejército, el de los paramilitares al servicio de los caciques locales del PRI y el de los intelectuales y servicios mediáticos incómodos por la ruptura del sueño de la modernidad que trajo la insurgencia zapatista» (1998a: 686). El movimiento neozapatista y, sobre todo, su persecución por parte del gobierno comenzó a obsesionar al Vázquez Montalbán periodista: «Atención a Chiapas porque allí se está jugando el sentido ético de este fin de milenio, como un referente simbólico, como un imaginario, si se quiere, de la esperanza como virtud laica» (1998b), escribió en una de estas cuatro columnas, publicada el 12 de enero. Según cuenta en Marcos, con la matanza de Acteal producida en medio de su correspondencia con el subcomandante, no solo no tuvo respuesta alguna, sino que llegó a dudar que este último estuviera vivo; aplazó incluso su viaje a México (2001a:37-38). Aun así, meses después, en julio de 1998, obtuvo el acuse de recibo de sus libros al leer cómo Marcos, en su comunicado «México 1998. Arriba y abajo: máscaras y silencios» del día 17, citaba varias líneas de Panfleto desde el planeta de los simios al referirse a aquellos intelectuales que apoyan y pretenden ser el sustento crítico del neoliberalismo gubernamental. A comienzos del año siguiente, recibió un nuevo mensaje del líder zapatista, quien le comunicaba que podía recibirle en la selva chiapaneca antes del 15 de febrero de 1999.

13 «Chiapas» (29/12/1997), «Chiapas» (12/01/1998), «Soberanías» (02/03/1998) y «Chiapas» (15/06/1998). 
Los puentes entre Manuel Vázquez Montalbán y el Ezln: cronología e intercambio...

\section{Marcos: El señor de los espejos: génesis e ideario en torno al EZLN}

Fruto de todo aquel intercambio epistolar, que se complementaría con las columnas de Vázquez Montalbán en El País, el escritor tomó la decisión de viajar a México para entrevistar al subcomandante. Como ya le sucedería con la escritura de $Y$ Dios entró en La Habana, para lo cual viajó a Cuba, desde mediados de los años noventa «en mí estalla una voluntad de volver a entender el mundo que me rodea - escribe Vázquez Montalbán - [...]. Todo eso obliga, o al menos a mí me obligaba, a un encuentro físico con esa cuestión» (en Tyras, 2003: 203, 205). La entrevista con Marcos se anunció en El País (17/02/1999) y gran parte de ella se publicó en el mismo diario con el título de «Marcos, el mestizaje que viene» $(21 / 02 / 1999)^{14}$, pero su encuentro debió producirse durante la segunda semana de febrero, pues en Marcos escribió: «Dejo instrucciones para que la revelación de mi encuentro con Marcos y las fotografías se publiquen cuando ya me haya ido de México» (2001a: 326). Aun así, su llegada al país ya la había anunciado en su nueva columna en El País titulada, precisamente, «México» (15/02/1999):

Confieso mi nostalgia de México cuando hay ocasión [...]. También asumo la relectura de la globalización a la que ha obligado la insurgencia zapatista, un favor que el zapatismo ha hecho a todos los condenados a ser globalizados en las peores condiciones. Me duele que México haya exportado al PRI como metáfora de la doble verdad, el doble lenguaje y la doble contabilidad, o que el país que mejores gritos ha lanzado a favor de la libertad figure en los censos de Amnistía Internacional porque sus Gobiernos han violado derechos humanos. [...] Chiapas es la nueva poética de la insurgencia, sobre todo si se asume sin sectarismos ni dogmatismos, como síntoma del desorden imperante, que debe ser reordenado para que la globalización sea algo más que un neoimperialismo maquillado (Vázquez Montalbán, 1999b).

\footnotetext{
14 Asimismo, retazos de aquella entrevista aparecieron además en «Encuentro con el subcomandante Marcos» (Le Monde Diplomatique, n. ${ }^{\circ} 45-46$, agosto de 1999) y en «El subcomandante Marcos y yo ante el espejo» (Qué Leer, n. ${ }^{\circ}$ 40, 2000). También, Vázquez Montalbán recibió varias críticas sobre su encuentro con el subcomandante y su apoyo explícito a la causa neozapatista. De entre todas ellas, caben destacar los textos publicados en El País por Carlos Rodríguez Braun, «Marcos, Vázquez Montalbán y el liberalismo» (06/03/1999), y «Máscaras en la selva», de Antonio Elorza (24/11/1999). Haciendo gala de su sarcasmo más mordaz, Vázquez Montalbán les respondió a ambos aprovechando su espacio en dicho diario con los textos «El catedrático, Marcos y el chorizo» (13/03/1999) y «Melancólica alarma» (26/11/1999), respectivamente.
} 
La entrevista mantenida con el subcomandante en la Selva Lacandona se recogió de manera íntegra en Marcos, publicado en septiembre de 1999. Aun así, aunque se mantenga la estructura característica de la entrevista, lo que realmente mantuvieron Marcos y Vázquez Montalbán fue un diálogo, en el cual el escritor reafirmó y amplío su discurso en torno al neozapatismo que ya había venido construyendo en sus textos en prensa. Fundamentalmente, dentro de la era de la posmodernidad, cuya definición toma de Adolfo Sánchez Vázquez - «la posmodernidad como un interregno que ha habido entre dos modernidades diferentes, aunque se le ha llamado posmodernidad porque a todo fenómeno cultural se le ha de poner un estuche para poder comercializarlo» (Vázquez Montalbán, 2001a: 279) -, el escritor ve el neozapatismo como una nueva propuesta ética y política de «una izquierda deconstruida» (2001a: 323) y enmarcada dentro de la crisis del socialismo - el europeo, sobre todo; como afirma Carlos Montemayor, «si no hubiera ocurrido en los países de la Europa del Este la debacle del llamado socialismo real, las propuestas del EZLN se hubieran situado en la vanguardia socialista» (1998: 203) $-{ }^{15}$ en una era completamente globalizada. Y de esta nueva propuesta destaca «la convocatoria de la sociedad civil como el sujeto histórico que debe exigir un cambio de los procedimientos y objetivos políticos» (2001a: 171-172), lo cual sirve como respuesta a uno de los problemas de la izquierda a finales del s. Xx, como ya había planteado en su Planfleto desde el planeta de los simios: «En la primera revolución industrial el sujeto histórico de cambio era obvio, la clase obrera, pero hoy delimitar quién o quiénes componen ese sujeto histórico de cambio es uno de los problemas previos para la reconstrucción de cualquier filosofía transformadora» (1995: 42). Asimismo, Vázquez Montalbán valora sobremanera el carácter tanto simbólico como metafórico no solo del lenguaje del EZLN, condensado en los textos del subcomandante, a quien ve además como «un mestizo de razón dialéctica y simbolismo» (2001a: 104), sino también de sus acciones y sus imágenes. Considera, por ejemplo, que el «estar avalado

\footnotetext{
15 «Tengo bastante leído a este submilitar y no le he pillado en ningún desliz de argot convencional marxista-leninista», opina el escritor sobre Marcos (Vázquez Montalbán, 2001a: 41). De todos modos, es innegable para él la renovación que supone el EZLN a los planteamientos de la izquierda histórica — «Lo de Chiapas, como síntoma, es una nueva modernidad [...] crítica y estratégica de la izquierda» (2001a: 320) - , pues, en palabras de Carlos Taibo, el neozapatismo «defiende, sin embargo, un socialismo distinto del avalado por la socialdemocracia europeo-occidental y por los sistemas de tipo soviético, algo que acerca al anarquismo muchas de sus percepciones. Postula un socialismo indígena, un socialismo de los pobres, que en buena medida bebe de las tradiciones comunales de los mayas» (2018: 156).
} 
por una actitud de desafío simbólicamente armado» (2001a: 280) es lo que ha logrado el respaldo mediático y la atención hacia los planteamientos neozapatistas, así como el empleo del pasamontañas, que «alcanza un nivel polisémico de expresión. La máscara primero es un elemento defensivo para que los represores no os identifiquen, pero llega un momento en que eso es lo de menos. La máscara deviene metáfora. La sociedad está enmascarada y vuestra máscara le ayuda a contemplar su propio rostro enmascarado» (2001a: 199). La misma idea la aplica a lo que denomina indigenismo, es decir, a la rebelión indígena ${ }^{16}$ : el indígena, gracias al neozapatismo, se ha convertido en «realidad y en metáfora del globalizado» (2001a: 40), de un nuevo perdedor histórico fruto de las políticas neoliberales, lo cual da pie a una dialéctica mundial entre el globalizador y el globalizado; «por eso - en palabras de Montemayor - , la lucha del EZLN, el valor de los indios zapatistas en Chiapas, no solamente compete a México» (1998: 221).

Pero posiblemente la metáfora más destacada para Vázquez Montalbán del neozapatismo, y que dará título a su libro, sea la del espejo ${ }^{17}$, que toma de las alusiones que hace Marcos en sus comunicados al espejo traspasado de la obra Alicia en el país de las maravillas. De ese modo, escribe en Marcos que el ELZN plantea «un espejo no trucado para México, pero también para el mundo» (2001a: 150), «un espejo de la culpabilidad del sistema» con el que el neozapatismo rompe la lógica de aquel (2001a: 224). Y de ahí que sentencie que «de las manos de Marcos brotan los espejos y en cada uno de ellos un fragmento de la rotura de la utopía del paraíso neoliberal y del proyecto social-liberal» (2001a: 337).

\section{Referencias bibliográficas}

Balibrea Enríquez, Mari Paz (2002), «Escrituras de la globalización. Espacio y tiempo en la obra reciente de Manuel Vázquez Montalbán», en Claude Ambroise y Georges Tyras (eds.), Violence politique et écriture de l'élucida-

\footnotetext{
16 En este sentido, apunta Weselina Gacinska que «la resignificación del término "indigenismo" en Vázquez Montalbán es parcial. El autor, utilizando esta denominación para referirse a la lucha indígena, lo que trata es de subsanar las políticas nocivas hacia las comunidades, y realiza una labor importante de reivindicación e inversión de roles. Sin embargo, las imágenes ofrecidas [en Marcos] inevitablemente están vinculadas con una tradición occidental, y los imaginarios culturales indígenas son adaptados para el lector europeo» (2020: 44).

17 Como establece Colmeiro, «la imagen de los espejos trucados, deformadores y falsificadores de la realidad» ya había aparecido en la obra montalbaniana Cuestiones marxistas, publicada en 1974 (2014: 138).
} 
tion dans le bassin méditerranéen. Leonardo Sciascia et Manuel Vázquez Montalbán, Grenoble, Presses de la Univeristé Stendhal, págs. 207-220.

Buschmann, Albrecht (2020), «El espejo empañado: Y Dios entró en La Habana, entre reportaje literario y remodelación autoficcional», en MVM: Cuadernos de Estudios Manuel Vázquez Montalbán, 5, págs. 46-66.

Colmeiro, José (2010), «De Pepe Carvalho al Subcomandante Marcos: la novela policíaca hispánica y la globalización», en Revista Iberoamericana, LXXVI, 231, págs. 477-492.

- (2013), El ruido y la furia. Conversaciones con Manuel Vázquez Montalbán, desde el planeta de los simios, Madrid / Frankfurt am Main, Iberoamericana / Vervuert.

- (2014), Crónica general del desencanto. Vázquez Montalbán - Historia y ficción, Madrid, Anthropos.

GACiŃSKA, Weselina (2020), «Los movimientos indígenas y la globalización en los reportajes de Manuel Vázquez Montalbán», en MVM: Cuadernos de Estudios Manuel Vázquez Montalbán, 5, págs. 26-45.

Geli, Carles y Mauri, Marcel (2008), El periodismo según Manuel Vázquez Montalbán, Barcelona, Ronsel.

LARIO BASTIDA, Manuel (2019), «Anotaciones sobre un cuarto de siglo de cultura y comunicación política zapatista», en Tonos Digital: Revista de Estudios Filológicas, 36. En línea: www.tonosdigital.es/ojs/index.php/tonos/ article/view/2097/1027. Último acceso el 10-abr-2019.

Marcos, Subcomandante (1999), Don Durito de la Lacandona, San Cristóbal de las Casas, Centro de Información y Análisis de Chiapas.

- (2004), “A Manuel Vázquez Montalbán”, en Enlace Zapatista. En línea: $\quad$ www.enlacezapatista.ezln.org.mx/2004/11/28/a-manuel-vazquez-montalban/. Último acceso el 22-mar-2019.

Martí-Olivella, Jaume (2007), «Más allá de la utopía: Vázquez Montalbán o la práctica literaria de la revolución después de la revolución», en José Colmeiro (coord.), Manuel Vázquez Montalbán: el compromiso con la memoria, Woodbrige, Tamesis Books, págs. 227-257. 
Mateos, Mónica, (1999), «El socialismo necesita renovar su lenguaje», en La Jornada, 29 de abril. En línea: www.jornada.com.mx/1999/04/29/cul-el. html. Último acceso el 11-nov-2020.

Montemayor, Carlos (1998), Chiapas, la rebelión indígena de México, Madrid, Espasa.

SALGADO, Francesc (2012), «El castigo de luchar por lo evidente», en Manuel Vázquez Montalbán, Obra periodística. Volumen III: Las batallas perdidas (1987-2003), ed. de Francesc Salgado, Barcelona, Debate, págs. 9-22.

- (2020), «La reflexión sobre Latinoamérica de Manuel Vázquez Montalbán en la prensa (1989-2003). Pensamiento único, disidencia y globalización», en MVM: Cuadernos de Estudios Manuel Vázquez Montalbán, 5, págs. 6-25.

TAibo, Carlos (2018), Anarquista de ultramar. Anarquismo, indigenismo, descolonización, Madrid, Catarata.

Tyras, Georges (2003), Geometrías de la memoria. Conversaciones con Manuel Vázquez Montalbán, Granada, Zoela.

VANDEN BERGHe, Kristine (2009), «Desde las montañas del sureste», en José Carlos González Boixo (ed.), Tendencias de la narrativa mexicana actual, Madrid / Frankfurt am Main, Iberoamericana / Vervuert, págs. 245-273.

VÁzQuez Montalbán, Manuel (1984), «Las señoritas del abanico», en El País, 27 de marzo. En línea: www.elpais.com/diario/1984/03/27/opinion/449186414_850215.html. Último acceso el 10-ene-2020.

- (1994a), «Chiapas», en El País, 9 de enero. En línea: www.elpais.com/diario/1994/01/10/ultima/758156402_850215.html. Último acceso el 2-oct2020 .

- (1994b), «La teología neoliberal», en El País, 5 de abril. En línea: www. vespito.net/mvm/teoneo.html. Último acceso el 11-abr-2019.

- (1995), Panfleto desde el planeta de los simios, Barcelona, Crítica.

- (1996), El premio, Barcelona, Planeta. 
- (1997a), «Prólogo. En defensa del romanticismo» a Pierre Kalfon, Che. Ernesto Guevara, una leyenda de nuestro siglo, trad. de Manuel Serrat Crespo, Barcelona, Plaza \& Janés, págs. 13-15.

- (1997b), «Chiapas», en El País, 29 de diciembre. En línea: www.vespito. net/mvm/chiapas5.html. Último acceso el 11-abr-2019.

- (1998a), Y Dios entró en La Habana, Madrid, El País / Aguilar.

- (1998b), «Chiapas», en El País, 12 de enero. En línea: www.vespito.net/ mvm/chiapas6.html. Último acceso el 11-abr-2019.

- (1999a), «Prólogo. Nota sobre globalizadores y globalizados» a Antonio Albiñana (ed.), Geopolítica del caos. Le Monde diplomatique, edición española, Madrid, Debate, págs. 11-21.

- (1999b), «México», en El País, 15 de febrero. En línea: www.vespito.net/ mvm/chiapas9.html. Último acceso el 11-abr-2019.

- (1999c), «Tam tam», en El País, 30 de agosto. En línea: www.elpais.com/ diario/1999/08/30/ultima/935964002_850215.html. Último acceso el 1-oct-2020.

- (2001a), Marcos: El señor de los espejos, Madrid, Punto de Lectura.

- (2001b), La literatura en la construcción de la ciudad democrática, Barcelona, Mondadori.

- (2012a), «El Che en el supermercado de la transgresión», en Obra periodística. Volumen III: Las batallas perdidas (1987-2003), ed. de Francesc Salgado, Barcelona, Debate, págs. 300-303.

- (2012b), «Zapatismo», en Obra periodística. Volumen III: Las batallas perdidas (1987-2003), ed. de Francesc Salgado, Barcelona, Debate, págs. 277-278.

VolpI, Jorge (2018), La guerra y las palabras. Una historia intelectual de 1994, Ciudad de México, Era. 